\title{
Cenografia no teatro e nos espaços expositivos: uma abordagem além da representação
}

\author{
Scenography in the theater and exhibition spaces: \\ an approach beyond representation
}

Elcio ROSSINI'

\section{Resumo}

A cenografia tem um papel importante no contexto contemporâneo dos museus, no entanto, sobre ela, recaem alguns equívocos e preconceitos ligados à ideia ultrapassada que limita cenografia à representação, à simulação e à teatralidade. Atualmente, os museus investem, cada vez mais, em espaços flexíveis que possam ser modificados e adaptados a cada novo projeto curatorial. A cenografia de exposições é um recurso que se constrói no espaço para oferecer ao visitante uma experiência sensível do conteúdo escolhido por meio da cor, dos percursos e das imagens. Este artigo analisa a cenografia em sua dimensão histórica, apresentando um panorama de sua evolução no teatro e sua aplicação contemporânea na Museologia.

Palavras-chave: Cenografia. Expografia. Museologia. Museus.

\begin{abstract}
Scenography plays an important role in the contemporary context of museums; however, there are some misconceptions and prejudices concerning the outdated idea that limits scenography to representation, simulation, and theatricality. At present museums increasingly invest in flexible spaces that can be modified and adjusted to any new curatorial project. The scenography of exhibitions is a resource built in a space to offer the visitor a sensitive experience of a chosen content through color, pathways, and images. This article analyzes scenography in its historical dimension presenting a panorama of its development in theater and its contemporary use in Museology.
\end{abstract}

Keywords: Scenography. Expography. Museology. Museums.

\section{Introdução}

Os conceitos que as palavras encerram se modificam com o tempo e com as transformações complexas das sociedades que as criaram. Algumas vezes, as palavras guardam resquícios de ideias passadas ou preconceitos que, por algum motivo, a elas aderiram, impondo distorções e equívocos. Isso acontece, por exemplo, com a palavra cenografia, que, por um longo período da história do teatro ocidental, esteve identificada com a representação pictórica do espaço tridimensional. Atualmente, cenografia não pode ser identificada apenas como um instrumento para representar espaços, lugares e objetos, tampouco sua aplicação está limitada à linguagem teatral da qual se originou.

O museu contemporâneo é, cada vez mais, um espaço flexível que se modifica e se adapta a cada nova

1 Professor Doutor, Universidade Federal de Santa Maria, Departamento de Artes Cênicas. Av. Roraima, 1000, Cidade Universitária, 97105-900, Santa Maria, RS, Brasil. E-mail: <elciorossini@yahoo.com.br>.

Recebido em 3/2/2012, reapresentado em 20/6/2012 e aceito para publicação em 2/7/2012. 
proposta curatorial; para isso, busca recursos em diferentes áreas do conhecimento. Os termos cenografia de exposições, arquitetura de exposições ou design de exposições são empregados para designar o trabalho de organização do espaço e das formas de expor um conteúdo. No entanto, do ponto de vista museológico, esses termos parecem carregar, exacerbadamente, as particularidades de suas origens, ou seja, teatro, arquitetura e design em detrimento do campo museológico. Outro termo, específico do campo museológico, criado por Desvallées em 1993 em substituição à "museografia", é "expografia" (Bary; Tobelem, 1998). Essa diversidade de termos demonstra que não há um consenso sobre como nomear a tarefa de dar forma expositiva a um determinado conteúdo. O objetivo deste texto é analisar especificamente a cenografia em sua dimensão histórica e sua aplicação contemporânea na Museologia.

Apesar de se constatar que a cenografia tem um papel importante no contexto dos museus, sobre esse termo recaem alguns equívocos e preconceitos ligados a uma ideia estanque e ultrapassada que limita cenografia à representação, à simulação e à teatralidade. Para se compreender a cenografia além da noção de representação, é necessário retomar sua origem histórica e sua evolução ao longo das principais transformações da linguagem teatral, desde sua origem no teatro grego até as experiências do final do século XIX.

A partir dessa perspectiva, pode-se investigar a noção de cenografia e suas correlações com conceitos da linguagem teatral e das artes visuais aplicadas às escolhas formais para apresentação do conteúdo de uma exposição. A cenografia está intimamente associada ao teatro, contudo ela não pode existir sem uma estreita ligação com as artes visuais e a arquitetura. Este artigo propõe uma reflexão situada no campo da Museologia, das artes visuais e do teatro.

\section{Cenografia, tradição e preconceito}

A cenografia, por séculos, foi sinônimo de representação pictórica. Com a urgência dos acontecimentos do século XX, transformou-se silenciosa e radicalmente a ponto de mudar seu escopo conceitual sem que se percebesse isso claramente.
No teatro, a noção de representação pode estar no ator que interpreta um personagem ou pode estar também no espaço cênico. A representação é algo que se coloca no lugar de uma ausência, "é o fenômeno mais geral, o que permite ao espectador ver 'por delegação' uma realidade ausente sob forma de um substituto" (Aumont, 1995, p.10). Um objeto ou espaço representado pode ser entendido como evocação, portanto deles escaparia algumas qualidades daquilo que substituem. Uma pedra cenográfica, por exemplo, não tem peso e não tem as marcas do tempo. Sua textura, cor e temperatura são meras imitações de um original distante.

O que significa representar, então, se não conduzir um objeto ausente à presença, suportá-lo na presença como ausente, controlar sua perda, sua morte pela e na representação e, ainda mais, dominar o desprazer ou a angústia de sua ausência no prazer de uma presença que toma o seu lugar? (Marin, 2001, p.311, tradução minha).

Na cenografia, a representação não está limitada à substituição de um original: ela é também um elemento narrativo, um auxiliar que permite situar espacial e temporalmente o tema abordado por um texto teatral ou por uma exposição.

Como todo fundamento do teatro ocidental, a cenografia tem origem no teatro grego. Os teatros gregos foram construídos nas encostas de colinas, compostos pelo theatron (local destinado ao público,"lugar de onde se vê") e pela orchéstra (área circular onde o coro atuava). Nos primeiros teatros, uma tenda localizada em oposição frontal ao público recebia o nome de skené. A skené, "na tangente da primitiva arena grega, foi o primeiro elemento estrutural introduzido no espaço cênico, seguindo-se, ao longo da história, por número crescente de recursos destinados à delimitação da área de representação" (Souza, 2003, p.32). Essa tenda era utilizada para os atores trocarem de roupa e servia de local para guardar o figurino. Mais tarde, evolui para uma construção em pedra, acrescida, posteriormente, de outros elementos arquitetônicos. A construção de pedra ganhou colunas, portas e uma plataforma onde os atores desenvolviam as cenas das tragédias e comédias gregas. Durante o período em que a skené ainda era uma tenda de lona, sobre ela era aplicada uma pintura, graphos, representando, ao que tudo indica, a fachada de um palácio ou templo. Graphos somada a skenévai produzir a palavra cenografia. 
Na Idade Média, o teatro, como um edifício construído especificamente para prática teatral, desapareceu, e as encenações da vida dos santos e outros eventos religiosos eram realizadas no átrio das igrejas; mais tarde, ao saírem do interior da igreja, essas encenações passaram a ser realizadas em carroções dispostos pelas ruas ou praças da cidade. Cada um deles representava um espaço específico, um conjunto de estações para narrar os temas religiosos. Como pequenos teatros, essas estações, também chamadas de "casas ou residências", eram utilizadas sucessivamente de acordo com as narrativas (Surgers, 2007, p.64, tradução minha).

No século XVII, o teatro adquire sua forma mais duradoura com a criação do teatro à italiana. A encenação ganha um edifício específico, no qual "existe uma separação, por um lado simbólica e por outro material, entre os espectadores e a representação" (Surgers, 2007, p.64, tradução minha). A plateia está construída na forma de uma ferradura, em que o rei ocupa o centro e tem visão frontal e privilegiada da encenação. No teatro à italiana, a disposição da plateia, formada por camarotes, galerias e, tardiamente, poltronas, fixava uma hierarquia social. Assim, a visibilidade que cada espectador tinha da encenação correspondia ao seu poder econômico e político.

Amparada pela invenção renascentista da perspectiva, a cenografia teatral foi, desde a invenção do teatro à italiana, do século XVII até o final do século XIX, a produção de uma ilusão pictórica do espaço tridimensional. A planura absoluta de uma tela, colocada no fundo do palco, representava a paisagem natural, a fachada ou o interior de um palácio. Como aliada da ilusão visual produzida pela perspectiva, havia uma iluminação frágil feita com velas e candelabros. Um maquinário específico foi desenvolvido para produção de efeitos visuais, como as ondas do mar ou de um rio, nuvens suspensas e figuras aladas, entre outros. Três longos séculos salvaguardaram a concepção de cenografia como representação ilusória de lugares pintados num telão e colocados no fundo do palco. A persistência dessa abordagem restringia o papel do cenógrafo a um simples artesão que repetia determinados padrões para pintar paisagens e arquiteturas, utilizando a perspectiva e as técnicas de trompe-l'oeil. Bablet (1965) afirma que, naquele período, a cenografia não propunha uma reflexão sobre o espaço cênico, e, em consequência, a autoria do projeto cenográfico não ocupava um lugar de destaque nas montagens teatrais porque os telões que compunham a cenografia de um espetáculo podiam ser executados por mais de um atelier, e seu valor era estipulado por suas dimensões e pelos temas pictóricos encomendados. "O preço variava conforme a complicação do motivo pintado. Em 1895, um metro quadrado de céu ou de mar custava 6 francos; um metro de arquitetura normal, 10 francos, e um metro de arquitetura rica (o palácio dos Capuletos de Romeu e Julieta), 12 francos" (Bablet, 1965, p.101, tradução minha).

No final do século XIX, Appia (2000) publica "A música e a encenação", por meio do qual constata que os telões pintados eram um recurso pobre, que não explorava as potencialidades do espaço cênico. O surgimento da luz elétrica e seu uso no teatro, na segunda metade do século XIX, ofereceram novas possibilidades para as montagens teatrais e, ao mesmo tempo, revelaram a precariedade do espaço que a perspectiva pictórica procurava representar. Para Appia, a pintura em telões e a iluminação eram dois elementos que, ao invés de se enriquecerem mutuamente, excluíam-se. A luz elétrica desnudava os efeitos ilusionistas dos grandes telões posicionados no fundo do palco. Por sua vez, o espaço pictórico não oferecia recursos que pudessem enriquecer a ação dos atores e a encenação. Appia acreditava que a cenografia deveria ser um sistema de formas e de volumes reais que proporiam ao ator a necessidade de achar soluções plásticas e expressivas para agir sobre o espaço cenográfico. Em seus projetos, aboliu o telão pintado do fundo do palco e criou espaços compostos de rampas, escadas e elevações do piso, que obrigavam o corpo a dominar as dificuldades deles resultantes e a transformar tais dificuldades em formas expressivas. Com esses elementos, Appia criou "espaços rítmicos".

O século XX, a partir das propostas de Appia, trouxe inúmeras mudanças ao teatro e, em consequência, à noção de cenografia, a qual foi, aos poucos, sendo desvinculada da obrigação de representar espaços internos ou externos. Atualmente, a cenografia vai além da representação, e seu campo expandiu-se para incluir uma gama maior de possibilidades. No entanto, a noção de representação pictórica e seus limites estabelecidos aderiram de tal forma ao conceito de cenografia que, hoje, é necessária uma reflexão teórica sistemática para demonstrar que pensar cenografia apenas como representação é um equívoco que não pode mais ser mantido. 
Constata-se que a noção de representação pictórica como sinônimo de cenografia persiste como resíduo acumulado ao longo da história do teatro, tanto para o senso comum como para a produção, a crítica e a divulgação das artes no âmbito dos inúmeros segmentos vinculados à cultura que utilizam a cenografia como forma de comunicação e expressão.

Em "The antitheatrical prejudice", Barisch (1985) observa que é comum que se tome emprestado da arte termos para qualificar positivamente pequenas coisas da vida cotidiana, como "poético," "lírico," "musical". A exceção são os termos oriundos do teatro, como "melodramático", "atuar", "fazer uma cena" e assim por diante, que são utilizados para hostilizar, depreciar ou expressar desaprovação. Da mesma forma, a palavra cenografia é empregada para apontar a superficialidade de um lugar. É comum se ouvir, pejorativamente, por exemplo, que algo está muito cenográfico ou é "pura cenografia".

O texto "Objetualidade", de 1967, notabilizou Fried (2004) por não ter compreendido o significado do que estava sendo formulado, naquela oportunidade, pelos artistas minimalistas e do campo geral da arte contemporânea. Nele, Fried (2004) identificou a presença nociva do teatro nas obras minimalistas. Segundo ele, algo de pernicioso proveniente do teatro estava comprometendo a arte. Sobre essa questão, Fried (2004, p.179) afirma que"o teatro e a teatralidade não estão hoje em guerra, simplesmente, com a pintura modernista (ou com a pintura e a escultura modernistas), mas, sim, com a arte como tal".

A teatralidade que Fried aponta como um aspecto nocivo presente nas obras minimalistas é, em primeira instância, uma qualidade inerente ao teatro. Pode-se, ao longo da história, traçar, dentro e fora do teatro, o desenvolvimento da noção de teatralidade, todavia é importante considerar que o termo não existia antes de 1837, quando Thomas Carly o introduziu em seu livro "French revolution" (Glytzouris, 2008, p.139). Segundo Barthes (2003, p.54), teatralidade é o teatro menos o texto. "Uma espessura de signos e de sensações que se edifica em cena a partir do argumento escrito, é essa espécie de percepção ecumênica dos artifícios sensuais, gestos, tons, distâncias, substâncias, luzes, que submerge do texto sob a plenitude de sua linguagem exterior".

O teatro, excluído por Fried do campo da arte, estava sendo responsável por uma contaminação na "pureza" da arte modernista. O argumento foi fornecido por Morris (Fried, 2004, p.178), quando o artista percebeu a importância do espaço que circundava as obras e a presença do espectador como uma "atualidade em processo" e refletiu sobre ela. Para Morris, as obras minimalistas dialogavam com o espaço circundante, o que antes as obras de arte não faziam: "O melhor das novas obras cria relações fora da obra e faz com que estas sejam uma função do espaço, da luz e do campo de visão do espectador" (Fried, 2004, p.179). O contexto de inserção das obras, segundo Morris, ganhava relevo e elas não podiam mais ser vistas como algo absolutamente independente do lugar onde estavam expostas; dessa forma, surgiu uma relação entre o objeto artístico e o lugar no qual era exposto.

Se a obra existe em um contexto de relações que inclui o lugar e o observador, então uma contaminação atingiu a pureza da obra, ou seja, o ambiente que acolhe a obra funcionava como um cenário e, portanto, lançava, sobre as obras expostas, valores exteriores a elas. A esse respeito, Fried (2004, p.185) escreve:

\begin{abstract}
A menos que as obras sejam colocadas em um contexto totalmente natural, algo que Morris não parece preconizar, deverá construir-se algum tipo de cenário artificial, ainda que este seja completamente arquitetônico. O que os comentários de Smith parecem sugerir é que, quanto mais impressionante seja o cenário construído - o que equivale a dizer, impressionante como teatro -, mais supérfluas se tornam as obras.
\end{abstract}

O equívoco de Fried reflete sua incapacidade de compreender transformações que o campo artístico propõe constantemente. É curioso que, passado meio século e depois de o texto ter sido inúmeras vezes criticado e ter dado suporte para importantes debates críticos nas artes visuais, ainda é possível encontrar vigentes pensamentos semelhantes aos de Fried. O preconceito sobre a cenografia chega até os dias atuais toda vez que se emprega pejorativamente a palavra para designar simulação ou imitação.

\section{Cenografia expandida}

Atualmente, a revisão do termo cenografia e de seu escopo é fundamental. Observa-se que, na língua francesa e inglesa, as palavras empregadas para designar cenografia, décor eset design, respectivamente, estão sendo 
substituídas pelos termos originais scénographies e scenography. Em francês, a palavra décor - ornamentação, pintura, pano de fundo - foi, por longo tempo, a forma mais usual de nomear cenografia. A palavra décor determinava uma restrição, ou melhor, refletia o pensamento de uma época quando cenografia era apenas uma tela pintada para preencher o fundo do palco. Sua função era oferecer ao público a ilusão do espaço aberto de um jardim ou da sala de um palácio com o uso da perspectiva e de trompe-l'oeil.

Décor de thèâtre é uma expressão que manteve, e ainda insiste em manter, a cenografia presa, em algumas instâncias, aos limites técnicos e conceituais que começaram a desaparecer no final do século XIX, com as propostas de Adolphe Appia e Gordon Graig. Constata-se o empenho dos teóricos para substituir a palavra décor devido ao expressivo número de livros publicados sobre cenografia, em língua francesa, que passaram a utilizar a palavra scénographie.

A reflexão teórica recente sobre cenografia tem buscado termos e conceitos aplicados às artes visuais para corresponder à amplitude que o termo adquiriu. Não foi por acaso que a mais importante mostra internacional de cenografia, a $11^{\text {a }}$ Quadrienal de Praga, propôs o simpósio "Scenography Expanding" com o objetivo de deflagrar um discurso transdisciplinar sobre a noção de cenografia. No folder de divulgação do evento realizado em Riga, Belgrado e Évora, - Scenography Expanding Symposia (2010, online) -, publicado em língua portuguesa, pode-se ler que:

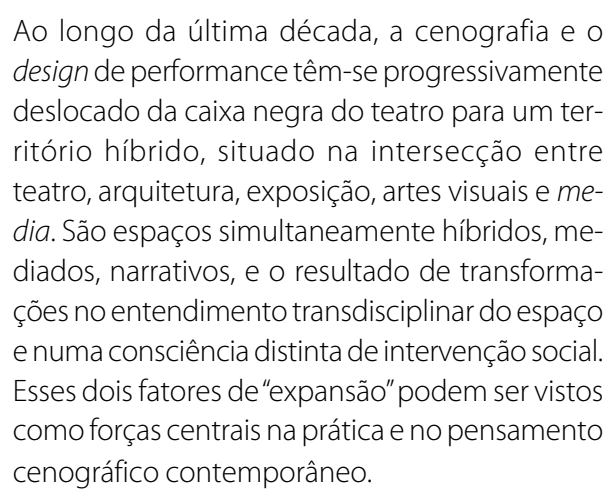

Tanto no título do simpósio, "Scenography Expanding", como no texto de divulgação, percebem-se relações com o conceito de Escultura no Campo Expandido (Sculpture in the Expanded Field) que foi desenvolvido por Rosalind Krauss em 1979 (Krauss, 1984, p.128). No final da década de 1970, Krauss, motivada por um problema semelhante ao da cenografia contemporânea, investigou trabalhos tridimensionais que estavam sendo produzidos na época e que não podiam se acomodar na definição tradicional de escultura.

Nos últimos dez anos, coisas realmente surpreendentes têm recebido a denominação de escultura: corredores estreitos com monitores de TV ao fundo; grandes fotografias documentando caminhadas campestres; espelhos dispostos em ângulos inusitados em quartos comuns; linhas provisórias traçadas no deserto. Parece que nenhuma dessas tentativas, bastante heterogêneas, poderia reivindicar o direito de explicar a categoria escultura. A não ser que o conceito dessa categoria possa se tornar infinitamente maleável (Krauss, 1984, p.129).

O desenvolvimento de novas práticas utilizadas pelos artistas visuais desde a década de 1960 exigiu uma reflexão que pudesse compreender a ampliação do conceito de escultura que se ligasse à ideia moderna de pureza dos meios de expressão e à especialização técnica. A cenografia contemporânea encontra um problema semelhante para compreender sua transdisciplinar inserção nos diferentes segmentos e manifestações culturais contemporâneas.

A reflexão que procura redimensionar o conceito de cenografia para revelar a complexa gama de proposições vinculadas a ela não encontrou ainda uma nomenclatura própria e adequada; dessa maneira, toma de empréstimo termos oriundos das artes visuais para poder discutir suas questões mais urgentes. Possivelmente, o que leve os teóricos a buscarem, nas artes visuais, conceitos que, por várias razões, ajustam-se ao campo cenográfico atual seja a estreita aproximação deste com as questões contemporâneas das artes visuais. Como classificar as cenografias de experiências teatrais realizadas especialmente para lugares específicos, como presídios e banheiros públicos, lugares que contêm cargas semânticas, imagéticas e sensoriais próprias e intransferíveis? São espetáculos pensados para os lugares escolhidos e não poderiam, em hipótese alguma, acontecer num palco convencional. Para citar um exemplo brasileiro, há o trabalho realizado pelo Teatro da Vertigem em igrejas, hospitais e num percurso pelo poluído rio Tietê, na cidade de São Paulo, entre outros espaços específicos utilizados na criação e montagem do grupo. Ali a cenografia escolhe e determina áreas para atuação, seleciona e produz objetos; não há dúvida de que, nesse caso, a cenografia 
não representa nada, não imita ou simula. O termo site specific, oriundo das artes visuais, pode ser aplicado com propriedade e justeza em experiências dessa natureza. Tomar de empréstimo termos já incorporados ao vocabulário das artes visuais é salutar porque demonstra a afinidade entre as categorias e pode corroer concepções rígidas que identificam cenografia apenas como representação de algum lugar ou de alguma coisa.

\section{Museus e cenografias}

Expografia, termo criado por Desvallées em 1993, vem sendo utilizado com frequência como complemento do termo Museologia,'para designar a exposição e tudo que diz respeito a sua espacialização, portanto, tudo que está em torno da exposição (excluindo as outras atividades museográficas, como a conservação, segurança etc.), e essas últimas se situam no museu ou em local não museal' (Bary; Tobelem, 1998, p.221, tradução minha). 0 termo procura definir uma especificidade para os projetos de espacialização de uma exposição e as formas complementares de expor seu conteúdo, no entanto, parece não acrescentar nada que não esteja nos termos Cenografia de Exposições, Arquitetura de Exposições ou mesmo Design de Exposições.

Tem por objetivo a pesquisa de uma linguagem fiel para traduzir o programa científico de uma exposição. Nisso ele difere da decoração, que utiliza os objetos a serem expostos em função de um critério estético, e da cenografia que, exceto em algumas aplicações particulares, utiliza os objetos ligados a um programa científico como instrumentos de um espetáculo sem que eles sejam necessariamente o assunto central deste espetáculo (Bary; Tobelem, 1998, p.221, tradução minha).

Observa-se a preocupação do autor em distinguir a expografia de decoração e cenografia. As duas últimas abordariam a exposição com algum tipo de equívoco e superficialidade. A primeira ressaltaria o aspecto estético da distribuição dos objetos no espaço expositivo, e a segunda endossaria a posição da primeira, agravada pelo fato de imprimir, no espaço e nos objetos expostos, conceitos oriundos do teatro, como teatralidade, dramatização e representação, todos ligados à ideia de espetáculo.

No mesmo glossário, encontra-se o verbete"cenografia", que o autor definiu, partindo de sua origem grega, da seguinte forma: "de sua origem etimológica grega (skené = tenda, abrigo rústico edificado na cena do teatro grego), a cenografia é a arte de representar em perspectiva, portanto, a arte do palco" (Bary; Tobelem, 1998, p.242, tradução minha).

A definição é acertada quando menciona a origem grega, mas errônea quando afirma que cenografia é a arte de representar em perspectiva. Os autores Bary e Tobelem (1998) reafirmam essa definição, por meio de seu equívoco, ao aplicar a palavra como se ainda correspondesse a um procedimento específico utilizado entre os séculos XVII e XIX, o que nos indica a manutenção de um pensamento ultrapassado sobre cenografia.

Em "La Muséologie, histoire, développements, enjeux actuels", Gob e Drouguet (2010) reconhecem que é comum a cenografia ser considerada como um elemento puramente decorativo. O aspecto decorativo da cenografia é importante porque torna a visita de uma exposição agradável, aumenta o interesse e a atenção do visitante. No entanto, dentro de um projeto museográfico, a função da cenografia ultrapassa seu aspecto puramente decorativo. A exposição é uma mídia em três dimensões que se oferece para ser percorrida sensivelmente por cada um dos visitantes e cujo discurso se constrói no espaço. Cenografia traz a dimensão conceitual do espaço, propondo ritmos e atmosferas geradas pela organização do espaço, da iluminação e do som.

A cenografia contemporânea projeta e instaura novos espaços para serem vivenciados pela experiência direta do corpo, como afirma o cenógrafo português Ribeiro (2007, p.81):

Os diversos aspectos do trabalho cenográfico são
motivados pela questão da habitabilidade do
espaço, no sentido de sua natureza experimental
e/ou vivencial e consequentemente das suas
repercussões na percepção do corpo e do espa-
ço. [...] a cenografia é pensada como criação de
espaços que efetivamente possam ser habitados,
ao invés da concepção estática e unidirecional
dos cenários clássicos. Propõe-se atualmente uma
abordagem dinâmica e multidimensional da
cenografia, em que predomina, face a outros
modelos cenográficos eventualmente mais
canônicos, o universo dos objetos performáticos
eautônomos.

Procura-se, neste texto, construir um argumento que demonstre que a cenografia, nos últimos anos, teve um grande avanço técnico e conceitual e, atualmente, 
não se restringe a formas de representação e simulação. É compreensível que, no senso comum, mantenha-se uma noção arcaica do conceito de cenografia, pois muitos artistas importantes vêm colaborando para manter intacto o preconceito histórico sobre a cenografia através de seus trabalhos e, em especial, de sua incursão em campos distantes do teatro. Convidado pelo museu Boymans-Van Beuningen Museun, Rotterdam, Robert Wilson realizou a exposição Portrait, Still life, Landscape, em 1993, com uma seleção de obras da coleção do museu: esse trabalho ilustra a relação negativa que a cenografia, algumas vezes, tem com os projetos para exposições de arte devido ao fato de terem sido utilizadas as peças do museu como elementos cenográficos ou decorativos.

Em "O fim da história da arte", Belting (2006, p.141) comenta, com fina ironia, a exposição Portrait, Still life, Landscape, realizada por Robert Wilson:

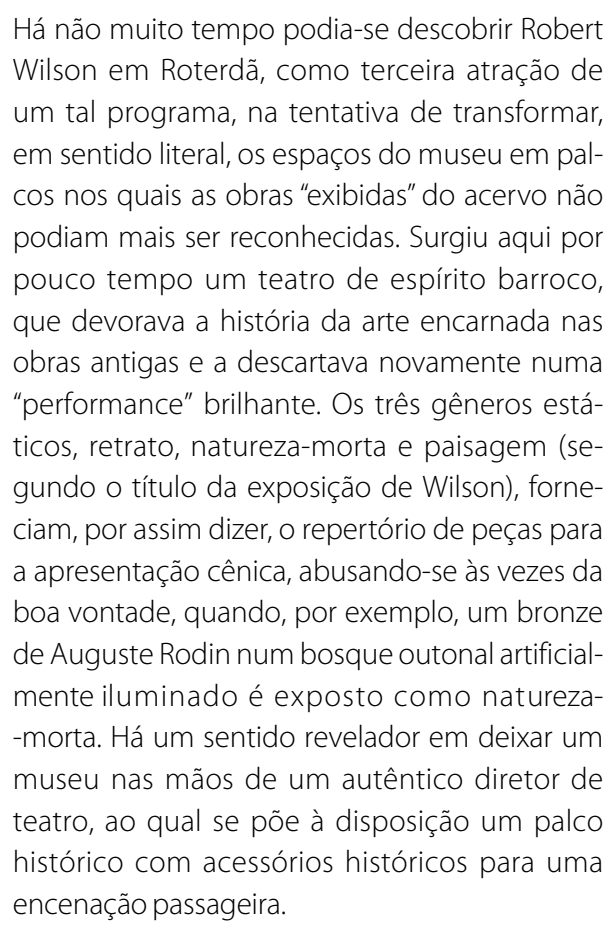

Na exposição, uma banalização das obras coloca em xeque o culto que o museu sempre impõe à apreciação das peças de sua coleção. No lugar do objeto de culto, um espaço ficcional e transitório foi montado como centro articulador da proposta curatorial. A primeira impressão é negativa. Como é possível expor uma escultura de Rodin como se fosse um personagem de um "bosque outonal"? Como tratar uma obra de referência para história da escultura moderna como um simples elemento cenográfico? Passada a indignação inicial, é possível analisar a proposição de Wilson com outros olhos, considerar o papel do espaço que acolhe, guarda e expõe os ícones de uma cultura. Belting, que faz sua aguda crítica à exposição Portrait, Still life, Landscape, do diretor teatral Robert Wilson, escreve sobre o museu:

O museu sempre foi o oratório privilegiado de uma coleção de originais que só tinham um único lugar no mundo. Nele foi quebrado o poder do presente e permutado pelo tempo da história. O lugar do museu situava-se, desse modo, fora do tempo dos seus visitantes e com tudo no interior da experiência espacial de seus corpos (Belting, 2006, p.141).

Essa concepção do museu tende a colocá-lo como "símbolo do lugar inalterável e do tempo suspenso" (Belting, 2006, p.140), concepção cada vez menos possível de ser sustentada porque os museus contemporâneos querem responder a um mundo de imediatos acontecimentos com exposições efêmeras e espetaculares, dessa maneira, atraindo a mídia e um público mais amplo.

\section{Conclusão}

A exposição Portrait, Still life, Landscape, de Wilson, poderia ser lida como uma proposta de reflexão sobre esse lugar de culto que o museu, ao longo de sua história, instituiu. Ali, onde tudo o que é exposto é coroado pela aura do intocável, raro e valioso. É bom lembrar que, superado o impacto inicial, passa-se a cultuar um reles urinol de porcelana branca, produto de um anonimato absoluto e multiplicado para o consumo imediato. O choque que esse objeto vulgar produziu, exposto num prosaico pedestal, mudou os rumos da história da arte, e vive-se, ainda hoje, animado pela reverberação desse choque provocado pela obra de Duchamp, em 1917². Possivelmente, a escultura de Rodin, que Robert Wilson colocou num falso bosque outonal, fora de seu confortável e

\footnotetext{
2 Em 1917, Marcel Duchamp envia para o Salão dos Independentes de Nova York um urinol assinado R. Mutt. Um mictório é retirado do mundo dos objetos ordinários e transportado para o domínio da arte pelo fato de ter sido assinado pelo artista. Para Duchamp, a escolha do objeto deveria recair sobre algo que não exercesse nenhum tipo de sedução estética. "O grande problema era o ato de escolher. Tinha que eleger um objeto sem que esse me impressionasse e sem a menor intervenção, dentro do possível, de qualquer ideia ou propósito de deleite estético" (Paz, 1997, p.27).
} 
seguro espaço protegido pela aura do intocável, permita ver sua fragilidade ou, ao contrário, sua contundente força expressiva: isso se a arte puder prescindir do complexo sistema que a sustenta.

A polêmica sobre a maneira correta e respeitosa de expor objetos no museu, proposta por Robert Wilson, em sua Portrait, Still life, Landscape, não é um fato isolado. Outras propostas semelhantes tencionam a adequação do projeto de uma exposição e o valor e supremacia das obras e objetos selecionados para exposição.

No entanto, há um consenso para exposições de arte e objetos raros. Na maior parte dos casos, o responsável pelo projeto, que pode ser o cenógrafo, o arquiteto, o artista ou o designer, deve preservar alguma sobriedade na escolha dos materiais, cores e organização espacial, os quais possam acolher e mostrar, da melhor forma possível, as peças escolhidas. O ideal contemporâneo defendido e desejado, especialmente pelos artistas e curadores,

\section{Referências}

APPIA, A. La música y la puesta en cena. Madrid: La Asociación de Directores de Escena de España, 2000.

AUMONT, J. A imagem. Campinas: Papirus, 1995.

BABLET, D. Estétique générale du décor de théâtre de 1870 à 1914. Paris: Centre Natinal de La Recherche Scientifique, 1965.

BARISCH, J. The antitheatrical prejudice. London: University of California, 1985.

BARTHES, R. Ensayos críticos. Buenos Aires: Planeta, 2003.

BARY, M.O.; TOBELEM, J.M. Manuel de muséographie: pepit guide à I'usage des responsables de musée. Biarritz: Option Culture, 1998.

BELTING, H. O fim da história da arte: uma revisão dez anos depois. São Paulo: Cosac Naify, 2006.

FRIED, M. Arte y objetualidad: ensayos y reseñas. Madrid: A. Machado Livros, 2004.

KRAUSS, R. A escultura no campo ampliado. Revista Gávea, n.1, p.128, 1984. segue sendo o espaço com pouca interferência: paredes perfeitamente niveladas e com pé direito alto; um conjunto de elementos articulados para proporcionarem uma leitura do público focalizada nas obras expostas.

Se, para as exposições de obras de arte, a cenografia, quando cria um espaço ficcional, pode ser um concorrente que as deprecia e as coloca num segundo plano, como no caso citado, em outros, é a cenografia que apresenta e dá o acesso ao conteúdo de uma exposição. O problema não está em defender um termo em detrimento de outro, tampouco considerar que cenografia, arquitetura ou design implicam desvios ou excessos supérfluos no projeto museográfico. O que interessa é compreender que uma disciplina, no transcurso do tempo, modifica seu escopo conceitual e amplia suas possibilidades de aplicação. Esse é um pressuposto fundamental para pensar a cenografia no campo ampliado e sua aplicação contemporânea em áreas como a Museologia.
GLYTZOURIS, A. On the emergence of European avant-garde theatre. In: JUSTICE-MALLOY, R. Theatre history studies. Tuscaloosa: The University of Alabama, 2008. p.139.

GOB, A.; DROUGUET, N. La muséologie: histoire, développements, enjeux actuels. Paris: Armand Colin, 2010.

MARIN, L. On representation. Serra Mall: Stanford University, 2001.

PAZ, O. Marcel Duchamp ou o castelo da pureza. São Paulo: Perspectiva, 1997.

RIBEIRO, J.M. Arquiteturas em palco. Lisboa: Instituto das Artes e Almedina, 2007.

SCENOGRAPHY EXPANDING SYMPOSIA. 2010. Available from: <http://www.intersection.cz/res/data/001/000159.pdf>. Cited: Nov. 2011.

SOUZA, N. A roda, a engrenagem e a moeda: vanguarda e espaço cênico no teatro de Victor Garcia no Brasil. São Paulo: Unesp, 2003.

SURGERS, A. Scénographies du théâtre ocidental. Paris: Armand Colin, 2007. 